\title{
Perioperative management of a morbidly obese patient undergoing right upper lobectomy with poor pulmonary function: a case report
}

\author{
Liuwei Gao ${ }^{1}$, Changli Wang ${ }^{2}$, Bin Zhang ${ }^{2}$, Jingjing $\mathrm{Li}^{2}$, Dongsheng Yue ${ }^{2}$ \\ ${ }^{1}$ Department of Enhanced Recovery after Surgery, Tianjin Medical University Cancer Institute and Hospital, National Clinical Research Center for \\ Cancer, Key Laboratory of Cancer Prevention and Therapy, Tianjin, China; ${ }^{2}$ Department of Lung Cancer, Lung Cancer Center, Tianjin Medical \\ University Cancer Institute and Hospital, Key Laboratory of Cancer Prevention and Therapy, National Clinical Research Center of Cancer, Tianjin, \\ China \\ Correspondence to: Dongsheng Yue. Department of Lung Cancer, Tianjin Lung Cancer Center, Tianjin Medical University Cancer Institute and \\ Hospital, Huan-Hu-Xi Road, Ti-Yuan-Bei, He Xi District, Tianjin 300060, China. Email: yuedongsheng_cg@163.com.
}

\begin{abstract}
The incidence and prevalence of obesity is drastically increasing worldwide. Clinical surgeons treating cancer patients often encounter obese patients. However, cases of surgical lung cancer patients with morbid obesity and poor pulmonary function undergoing lobectomy have not been reported. A 75 -year-old woman was referred to our hospital on June 25, 2014 with a cough with blood in phlegm for 1 week. Staging positron emission tomography revealed an abnormal lesion indicating malignancy under the pleura of the upper lobe of the right lung. As the patient had chronic obstructive pulmonary disease (COPD) and was morbidly obese [body mass index (BMI): $40.1 \mathrm{~kg} / \mathrm{m} 2$ ], she had preoperative poor pulmonary function with a forced expiratory volume in 1s (FEV1) of 1.061 and diffusing lung capacity for carbon monoxide of 52.2. After 2 weeks of rehabilitation and treatment, respiratory function improved before surgery. The patient required thoracotomy so that right upper lobectomy with lymph node dissection under general anesthesia could be performed. However, on postoperative day 3, the patient was diagnosed with postoperative severe pneumonia with respiratory failure and cardiac insufficiency, and was transferred to the intensive care unit (ICU). After 72 postoperative days, the patient was discharged from hospital. The pathological diagnosis was invasive adenocarcinoma. Although the patient experienced severe postoperative complications, this case is useful for surgeons treating cancer patients because there are few reports discussing the perioperative management of morbidly obese patients with poor pulmonary function undergoing lung cancer radical resection. Further studies on lobectomy for morbidly obese lung cancer patients with poor pulmonary function are warranted to improve the treatment methods of these patients.
\end{abstract}

Keywords: Case report; morbidly obese; lung cancer; poor pulmonary function; perioperative management

Submitted Sep 24, 2020. Accepted for publication Apr 14, 2021.

doi: 10.21037/apm-20-2554

View this article at: http://dx.doi.org/10.21037/apm-20-2554

\section{Introduction}

The incidence and prevalence of obesity is drastically increasing worldwide, both in developed and in developing countries (1). Obesity refers to a degree of obvious overweight and excessive fat layer, which is a state caused by abnormal or excessive body fat accumulation $(1,2)$. The body mass index (BMI) is a simple diagnostic indicator for classifying overweight $\left(\mathrm{BMI}>25 \mathrm{~kg} / \mathrm{m}^{2}\right)$ and obesity in adults $\left(>30 \mathrm{~kg} / \mathrm{m}^{2}\right)$. Furthermore, patients with a BMI $\geq 40 \mathrm{~kg} / \mathrm{m}^{2}$ are defined as having extreme or morbid obesity $(1,2)$.

The current incidence of lung cancer remains high and is one of the leading causes of cancer deaths worldwide (3). At present, there are various treatment methods for lung 
cancer, including surgery, chemotherapy, radiotherapy, and targeted therapy, but surgery is still the main method for treating resectable lung cancer. In clinical practice, patients with lung cancer who have abdominal obesity are encountered, and it is often accompanied by poor pulmonary function, resulting in the slow recovery of postoperative cardiopulmonary function recovery, long bed time, and poor activity endurance, therefore greatly increasing the risk of complications, such as pneumonia, during the perioperative period. In the following case report, we present the perioperative management of a morbidly obese patient undergoing right upper lobectomy with poor pulmonary function, and review the relevant literature. We present the following article in accordance with the CARE reporting checklist (available at http:// dx.doi.org/10.21037/apm-20-2554).

\section{Case presentation}

A 75-year-old woman was referred to our hospital on June 25, 2014 with a cough with blood in phlegm for 1 week. Chest computed tomography examination revealed a lesion approximately $4 \mathrm{~cm}$ in size with marginal burrs under the pleura of the upper lobe of the right lung. Staging positron emission tomography confirmed an abnormal lesion indicating malignancy in the right upper lobe with no extrapulmonary disease. The patient had a history of smoking 20 cigarettes per day for 30 years, and she stopped smoking after hospitalization. She had several comorbidities, including hypertension, chronic obstructive pulmonary disease (COPD), bilateral knee arthritis, and morbid obesity with a BMI of $40.1 \mathrm{~kg} / \mathrm{m}^{2}$. Her hypertension was controlled with $10 \mathrm{mg}$ nifedipine tablets per day.

The patient was admitted to hospital to further undergo routine preoperative assessment, including blood routine, biochemistry tests, blood coagulation test, electrocardiographic examination and pulmonary function test. Respiratory function tests in June 2014 suggested obstructive impairment, with forced expiratory volume in $1 \mathrm{~s}\left(\mathrm{FEV}_{1}\right)$ of $1.06 \mathrm{~L}$, a $\mathrm{FEV}_{1}$ /forced vital capacity (FVC) percentage ratio $\left(\mathrm{FEV}_{1} \%\right)$ of 75.69 , and diffusing lung capacity for carbon monoxide $\left(\mathrm{D}_{\mathrm{LCO}} \%\right)$ of 52.2 . Blood gas test revealed arterial partial pressure of oxygen $\left(\mathrm{PaO}_{2}\right)$ at $81 \mathrm{mmHg}$, arterial partial pressure of carbon dioxide $\left(\mathrm{PaCO}_{2}\right)$ at $48.4 \mathrm{mmHg}$, and arterial hemoglobin oxygen saturation $\left(\mathrm{SaO}_{2}\right)$ at $93.7 \%$. Serum tumor marker test detected elevated carcinoembryonic antigen at $32.65 \mu \mathrm{g} / \mathrm{L}$.
No abnormal findings were detected in the other tests.

An intensive 2 -week rehabilitation program was conducted to improve respiratory function tests. After this period, she underwent further respiratory function tests, which revealed a $\mathrm{FEV}_{1}$ of $1.39 \mathrm{~L}, \mathrm{FEV}_{1} \%$ of 80.27 , and a $\mathrm{D}_{\mathrm{LCO}} \%$ of 56.8. The second blood gas analysis showed $\mathrm{PaO}_{2}$ at $85 \mathrm{mmHg}, \mathrm{PaCO}_{2}$ at $45.4 \mathrm{mmHg}$, and $\mathrm{SaO}_{2}$ at $95.4 \%$. The operation was scheduled as right upper lobectomy and lymph node dissection through thoracoscopy under general anesthesia. Unfortunately, the patient required conversion to thoracotomy so that right upper lobectomy could be performed due to the obese abdomen and extensive pleural adhesions, which resulted in a narrow space in the chest. Intraoperative protective mechanical ventilation was conducted, including tidal volume (TV) at $6-8 \mathrm{~mL} / \mathrm{kg}$, positive end-expiratory pressure (PEEP) at $5 \mathrm{cmH}_{2} \mathrm{O}$, and driving pressure at $13-14 \mathrm{cmH}_{2}$ O.Intraoperative ventilation adjustment was taken according to end tidal $\mathrm{CO}_{2}$ and arterial blood gas analysis. The patient recovered well after the operation and was sent to the post anesthesia care unit (PACU) after successful extubation in the operation room, where routine oxygen supplementation was applied. Oxygenation, respiratory ventilation, and cardiopulmonary circulation were all strictly monitored for at least $1 \mathrm{~h}$. The patient was then transferred to the general surgical ward for further observation and treatment when no adverse events appeared while in the PACU.

Sulbactam/ampicillin was used prophylactically after the operation due to complications associated with her medical history, including heavy smoking, morbid obesity, hypertension, and COPD. Unfortunately, the patient couldn't actively cough out sputum after surgery, therefore, fiberoptic bronchoscopy was performed to suck out sputum. The patient developed adverse symptoms on postoperative day 3 , including a fever of $38.6^{\circ} \mathrm{C}$, dyspnea, and yellow sticky sputum. Chest $\mathrm{X}$-ray showed patchy infiltrating shadow in the bilateral lower lung field (Figure 1A). The gas blood sample showed $\mathrm{SaO}_{2}$ at $87.7 \%, \mathrm{PaO}_{2}$ at $58.1 \mathrm{mmHg}$, and $\mathrm{PaCO}_{2}$ at $41.8 \mathrm{mmHg}$. Laboratory analysis of the blood revealed a white blood cell count of $13.24 \times 10^{9} / \mathrm{L}$, neutrophils at $91.7 \%$ and B-type natriuretic peptide at $1,203 \mathrm{~mL} / \mathrm{mL}$. The patient was diagnosed with postoperative severe pneumonia with respiratory failure and cardiac insufficiency. Due to her worsening condition, the patient was transferred to the intensive care unit (ICU), where she underwent tracheal intubation and mechanical ventilation to improve oxygenation and respiratory function. The broad- 

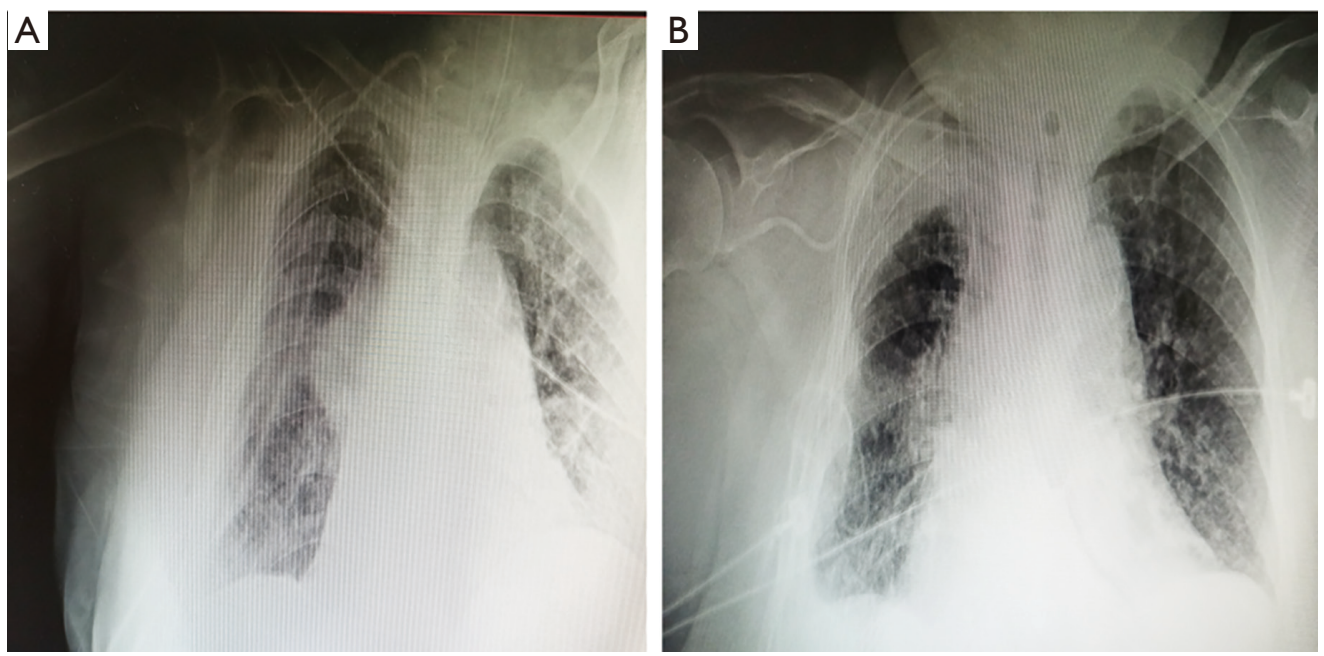

Figure 1 Representative chest X-ray photography before and after treatment. (A) Chest X-ray showed patchy infiltrating shadow in the bilateral lung field before treatment. (B) Chest X-ray indicated little shadows on the radiographs after treatment.

spectrum antibiotic, meropenem, was used for anti-infection treatment of the lungs, for the diagnosis of possible bacterial pneumonia resistant to sulbactam/ampicillin. Sputum was collected for bacterial culture and drug sensitivity test. Other major treatments involved sputum reduction with ambroxol, improvement of heart function with a moderate dose of diuretics and digoxin, nebulizing oxygen to relieve airway spasm, and an infusion of albumin for the treatment of hypoproteinemia. Based on the sputum culture results, which indicated Gram-negative bacilli and Candida albicans, meropenem was replaced with tazobactam/piperacillin and voriconazole on postoperative day 4. After these treatments, the patient's adverse clinical condition gradually disappeared along with little shadows on the radiographs (Figure 1B), and the patient was transferred to the general surgical ward on postoperative day 30 . However, due to weak sputum, adverse symptoms reappeared on postoperative day 33 . The patient was again transferred to the ICU again, where she underwent tracheotomy to expel sputum and other treatments similar to the previous occasion. After the second comprehensive treatment, the abnormal bilateral shadows on the chest $\mathrm{X}$-ray disappeared, and that was a significant improvement in her clinical condition on postoperative day 55 . The patient could get out of bed to exercise on postoperative day 57 , and to the general surgical ward for further rehabilitation on post-operative day 60 . After 72 postoperative days, the patient was discharged from hospital. The pathological diagnosis was invasive adenocarcinoma, pT2aN2M0.

All procedures performed in studies involving human participants were in accordance with the ethical standards of the institutional and/or national research committee(s) and with the Helsinki Declaration (as revised in 2013). Informed consent was obtained from the patient included in the study.

\section{Discussion}

In recent years, obesity has become a public health epidemic worldwide (1). The relationship between obesity and cancer had been studied, and some evidence shows that obesity might be associated with increased risk of malignant tumors and a high incidence of perioperative complications after oncologic surgery (4). The incidence of lung cancer remains high, and the cornerstone of most curative treatments for lung cancer is still lung resection surgery in patients with sufficient pulmonary reserves $(3,5)$. However, there are very few reports on the perioperative management of morbidly obese patient undergoing lobectomy with poor pulmonary function. Therefore, in the present study, we reported a case of a morbidly obese patient undergoing lobectomy with poor pulmonary function, and reviewed the perioperative complications and treatments.

Obesity puts significant pressure on the respiratory system in the form of chest and abdominal fat. The obese abdomen and the distribution of fat tissue in the chest area reduces the lung volume and impairs airway stability of the 
$(6,7)$. The weight of the abdomen against the diaphragm also hinders the normal range of diaphragm deflection (6). Eventually, these external forces lead to decreased lung compliance and inadequate gas exchange. Obesity is associated with cardiac disease, diabetes, respiratory diseases, hypertension, and stroke (6-9). In the early postoperative period of lung cancer, because of the patient's pain and obesity, weakened cough and sputum production and difficulty in turning over in bed are encountered. Following lobectomy, cardiopulmonary function is more vulnerable to damage, resulting in high cardiopulmonary complications. In their study, Bamgbade et al. showed that obesity is an independent risk factor for perioperative morbidity when comparing the incidence and severity of complications in obese and non-obese surgery patients (10). Similarly, De Jong et al. reported that morbid obesity (BMI $>40$ ) is one of the most important predictors of 30-day morbidity after surgery (9). Smoking is a known cause of COPD and increases the risk of postoperative complications and mortality (11). With an increase in the number of obese surgical patients, particularly those with COPD, there will be more postoperative complications, such as pneumonia, atelectasis, respiratory failure, myocardial infarction, and heart failure. Therefore, the need for perioperative and intensive care of obese surgical patients will increase significantly.

Rehabilitation and treatment strategies have been undertaken to reduce the incidence of perioperative complications for morbidly obese surgical lung cancer patients with COPD with poor pulmonary function $(12,13)$. In the present case, due the patient's medical history of morbid obesity and COPD, a 2-week rehabilitation program before surgery was conducted to improve respiratory function. The rehabilitation included smoking cessation, weight control, and moderate exercise (going up and down stairs and walking on flat surfaces). Nursing staff showed the patient how to perform thoracicmobility exercise, breathing control of diaphragm muscles, abdominal muscle wall work, and effective coughing. The patient received oxygen inhalation and nebulization therapy, including salbutamol, and inhaled budesonide at optimal doses. The perioperative use of prophylactic antibiotics was administrated. Our lung intraoperative protective strategy was then conducted, including low TV, low driving pressure, and an appropriate PEEP. Several reports indicated that a low TV combined with an adequate PEEP could minimize the incidence of postoperative pulmonary complications in obese patients $(14,15)$. Prophylactic measurement and treatment after lobectomy could also play an important role in reducing postoperative pulmonary and extrapulmonary complications. In our case, the major strategies implemented on the first day after surgery included semi-sitting position early mobilization, cough and deep breathing, high flow oxygen nasal cannula, aerosol inhalation, pain medicine, and proper nutrition.

However, the patient was diagnosed with postoperative severe pneumonia with respiratory failure and cardiac insufficiency on postoperative day 3. The main reasons for postoperative complications were considered. First, some perioperative rehabilitation and treatment plans were not implemented rigorously. For example, before surgery, patients should be encouraged to lose weight $(5-10 \%$ body weight) to prevent or treat obesity-related complications and to improve the surgeon's operating conditions $(12,16)$. In our case, a low-calorie diet was used to control the patient's weight, but the patient only lost $2 \%$ body weight before surgery. In addition, smoking cessation at least 4 weeks before surgery should occur to reduce postoperative pulmonary complications $(17,18)$; this was not consistent with the 2-week smoking cessation period for our case. Second, although respiratory function had improved before the operation, it did not reach the ideal state. Patients under consideration for major lung resection with preoperative $\mathrm{FEV}_{1}$ and $\mathrm{D}_{\mathrm{LCO}}<60 \%$ have been reported to have a high risk of postoperative complications $(19,20)$. Third, according to previously published studies, morbid obesity and COPD have been shown to be well-known risk factors for postoperative respiratory complications $(12,13)$. In our case, the patient was unable to actively cough out sputum after right upper lobectomy, which is considered one of the main postoperative lung cancer resection complications.

In conclusion, we present a case of a morbidly obese patient with poor pulmonary function who underwent right upper lobectomy for adenocarcinoma. Smoking is a known cause of COPD and lung cancer. Although the patient experienced severe postoperative complications, this is a useful case for surgeons to treat cancer patients, because there are few reports discussing the perioperative management of morbidly obese patients with COPD undergoing lung cancer radical resection. The case report is based on the perioperative care of only 1 patient. Further studies of lobectomy for morbidly obese lung cancer patients with poor pulmonary function are warranted to improve the treatment methods of these patients. 


\section{Acknowledgments}

Funding: The present study was supported by grants from the Doctoral Start-up Fund of Tianjin Medical University Cancer Institute and Hospital (No. B1802).

\section{Footnote}

Reporting Checklist: The authors have completed the CARE reporting checklist. Available at http://dx.doi.org/10.21037/ apm-20-2554

Conflicts of Interest: All authors have completed the ICMJE uniform disclosure form (available at http://dx.doi. org/10.21037/apm-20-2554). All authors report grants from Tianjin Medical University Cancer Institute and Hospital, during the conduct of the study.

Ethical Statement: The authors are accountable for all aspects of the work in ensuring that questions related to the accuracy or integrity of any part of the work are appropriately investigated and resolved. All procedures performed in studies involving human participants were in accordance with the ethical standards of the institutional and/or national research committee(s) and with the Helsinki Declaration (as revised in 2013). Informed consent was obtained from the patient included in the study.

Open Access Statement: This is an Open Access article distributed in accordance with the Creative Commons Attribution-NonCommercial-NoDerivs 4.0 International License (CC BY-NC-ND 4.0), which permits the noncommercial replication and distribution of the article with the strict proviso that no changes or edits are made and the original work is properly cited (including links to both the formal publication through the relevant DOI and the license). See: https://creativecommons.org/licenses/by-nc-nd/4.0/.

\section{References}

1. NCD Risk Factor Collaboration (NCD-RisC). Worldwide trends in body-mass index, underweight, overweight, and obesity from 1975 to 2016: a pooled analysis of 2416 population-based measurement studies in 128.9 million children, adolescents, and adults. Lancet 2017;390:2627-42.

2. Bray GA, Fruhbeck G, Ryan DH, et al. Management of obesity. Lancet 2016;387:1947-56.

3. Siegel RL, Miller KD, Jemal A.Cancer statistics, 2018. CA
Cancer J Clin 2018;68:7-30.

4. Bhaskaran K, Douglas I, Forbes H, et al. Body-mass index and risk of 22 specific cancers: a population-based cohort study of 5.24 million UK adults. Lancet 2014;384:755-65.

5. Majem M, Juan O, Insa A, et al. SEOM clinical guidelines for the treatment of non-small cell lung cancer(2018). Clin Transl Oncol 2019;21:3-17.

6. Salome CM, King GG, Berend N. Physiology of obesity and effects on lung function. J Appl Physiol (1985) 2010;108:206-11.

7. Zerah F, Harf A, Perlemuter L, et al. Effects of obesity on respiratory resistance. Chest 1993;103:1470-6.

8. Richardson TG, Sanderson E, Elsworth B, et al. Use of genetic variation to separate the effects of early and later life adiposity on disease risk: mendelian randomisation study. BMJ 2020;369:m1203.

9. De Jong A, Verzilli D, Chanques G, et al. Preoperative risk and perioperative management of obese patients. Rev Mal Respir 2019;36:985-1001.

10. Bamgbade OA, Rutter TW, Nafiu OO, et al. Postoperative complications in obese and nonobese patients. World J Surg 2007;31:556e560.

11. Licker MJ, Widikker I, Robert J, et al. Operative mortality and respiratory complications after lung resection for cancer: Impact of chronic obstructive pulmonary disease and time trends. Ann Thorac Surg 2006;81:1830-7.

12. Carron M, SafaeeFakhr B, Ieppariello G, et al. Perioperative care of the obese patient. Br J Surg 2020;107:e39-55.

13. Kim ES, Kim YT, Kang CH, et al. Prevalence of and risk factors for postoperative pulmonary complications after lung cancer surgery in patients with early-stage COPD. Int J Chron Obstruct Pulmon Dis 2016;11:1317-26.

14. Ball L, Hemmes SNT, SerpaNeto A, et al. Intraoperative ventilation settings and their associations with postoperative pulmonary complications in obese patients. Br J Anaesth 2018;121:899-908.

15. Eichler L, Truskowska K, Dupree A, et al. Intraoperative ventilation of morbidly obese patients guided by transpulmonary pressure. Obes Surg 2018;28:122-9.

16. Durrer Schutz D, Busetto L, Dicker D, et al. European practical and patient-centred guidelines for adult obesity management in primary care. Obes Facts 2019;12:40-66.

17. Lindström D, Sadr Azodi O, Wladis A, et al. Effects of a perioperative smoking cessation intervention on postoperative complications: a randomized trial. Ann Surg 2008;248:739-45. 
18. Barrera R, Shi W, Amar D, et al. Smoking and timing of cessation. Impact on pulmonary complications after thoracotomy. Chest 2005;127:1977-83.

19. Richter Larsen K, Svendsen UG, Milman N, et al. Exercise testing in the preoperative evaluation of patients with bronchogenic carcinoma. Eur Respir J 1997;10:1559-65.

Cite this article as: Gao L, Wang C, Zhang B, Li J, Yue D. Perioperative management of a morbidly obese patient undergoing right upper lobectomy with poor pulmonary function: a case report. Ann Palliat Med 2021;10(4):4959-4964. doi: 10.21037/apm-20-2554
20. Ferguson MK, Little L, Rizzo L, et al. Diffusing capacity predicts morbidity and mortality after pulmonary resection. J Thorac Cardiovasc Surg 1988;96:894-900.

(English Language Editor: R. Scott) 